\title{
EL ANIMAL QUE RÍE
}

\section{Luis Fernández Navarro \\ Universidad de Sevilla}

\begin{abstract}
Resumen: Este texto evalúa las semejanzas y, sobre todo, las diferencias entre «risa» animal y risa humana, reflexionando, a partir de la ciencia y la filosofía contemporáneas, sobre una vieja tésis aristotélica: que el hombre es el animal que ríe.

Palabras clave: risa, risa animal, risa humana, emoción, lenguaje.

THE ANIMAL THAT LAUGHS

Abstract: This paper evaluates the similarities and, above all, the differences between animal «laughter» and human laughter, reflecting, based on contemporary science and philosophy, on an old Aristotelian thesis: that man is the animal that laughs.

Keywords: laughter, animal laughter, human laughter, emotion, language

Recibido: 11 de abril de 2021

Aceptado: 21 de abril de 2021

DOI 10.24310/NATyLIB.2021.vi15.12341
\end{abstract}

Entre 1541 y 1547 , ya nadie sabe la fecha con certeza, Pierre Bunel visitó una conocida maison forte en tierras bordelesas. Humanista de Toulouse, hombre de gran reputación, extraordinario latinista, Bunel era considerado por sus contemporáneos el nuevo Cicerón. Había nacido en 1500 y se vio arrastrado, como tantos, a tomar partido en la gran controversia religiosa de la época. Se inclinó por la reforma al estilo erasmiano, y a pesar de no romper con el catolicismo tuvo que huir de Occitania para sufrir un exilio italiano, primero en Padua (1529), luego en Roma (1532) y finalmente en Venecia (1534). En 1537 regresó de su peregrinaje sin que cesase el hostigamiento por sus críticas al clero. Sumó entonces, alentado por De Bèze y Calvin, un acoso 
de signo contrario, debido a su permanencia en el seno de la Iglesia. Tiempos de polarización, malos tiempos.

La casa a que nos referimos, la que visita Bunel, estaba próxima a Saint Émilion. El erudito viajó hasta el Perigord para ver a su amigo y homónimo Pierre Eyquem. Eyquem, hombre «con más amor por las letras que conocimiento $^{1} »$, recibió del humanista el presente de un libro compuesto en un «galimatías de español con terminaciones latinas», la Theologia naturalis sive liber creaturarum, obra escrita un siglo antes con el título Scientia Libri Creaturarum por un tal Ramón Sibiuda, barcelonés, profesor de la Universidad de Toulouse. Este Libro de las Criaturas quedó intonso en la biblioteca de Pierre Eyquem, y quien lo leyó y lo tradujo al francés en 1569 fue su hijo Michel, encontrando en la obra «hermosas nociones», una «estructura bien secuenciada», un texto «sólido» y «acertado» para el establecimiento y demostración racional de las verdades religiosas. Michel Eyquem de Montaigne escribió una defensa de este texto en la que sostiene que no nos basta servir a Dios con el espíritu y el alma, sino que «le debemos y le rendimos también una veneración corporal». Aunque no es más que una descripción empírica del culto, es esta una tesis interesante y nos sirve para constatar una idea que recorre la obra del filósofo francés de forma permanente y obstinada: que el cuerpo, en el hombre, no puede ser negado ni superado. Idea que, dentro de poco, nos conducirá al núcleo de este artículo.

Anota Montaigne, citando a Sibiuda (o Sabunde, o Sebond), «no hay pieza en el mundo que desmienta a su hacedon»: el cielo, la tierra, los elementos, nuestro cuerpo, nuestra alma, «las cosas invisibles de Dios se manifiestan por la creación del mundo». Y añade: en la creación, los seres humanos no estamos solos, nos hallamos «en el piso más bajo de la casa», en el «más alejado de la bóveda celeste», pero no aislados, sino con los animales, «nuestros cofrades y compañeros». Por la virtud de nuestro entendimiento conocemos sus resortes internos y secretos. «Juego con mi gata», reflexiona Montaigne, en una cierta clave taoísta que él desconocía, y no sé «si es ella la que pasa el tiempo conmigo más que yo con ella». Rememora a Platón, su descripción de la Edad de Oro, y destaca, entre las principales ventajas del hombre de aquellos tiempos míticos, «la comunicación que tenía con las bestias». A los

\footnotetext{
${ }^{1}$ Para todas las referencias entrecomilladas que siguen, ver (Montaigne, 2014: 853 y ss).
} 
animales podía preguntarles para aprender, puesto que alcanzaba a interpretar «sus sonidos y movimientos». En nuestros días, sostiene, «hemos de observar la paridad que existe entre ellos y nosotros», pues «tenemos una mediana comprensión de lo que expresan» y también la tienen los animales de nosotros, «más o menos en la misma medida». Asimismo, entre los animales se da «una plena y total comunicación», «se entienden unos a otros, no solo dentro de la misma especie». En efecto, los animales revelan lo que sienten con su cuerpo y con distintos sonidos, sea el miedo, el dolor o un rapto de alegría. Igual lo hacemos los hombres con las manos, con la cabeza, con las cejas y los hombros, no solo con la voz. «¿Cuál de nuestras capacidades no reconocemos en la actividad de los animales?», se pregunta. Observa el filósofo sus sociedades reguladas con mucho orden, cargos, y funciones, como ocurre con las abejas laboriosas. Anota el discernimiento de las golondrinas al elegir entre mil lugares el emplazamiento de sus nidos. Celebra su juicio, porque ¿cómo «cogen agua y luego arcilla sin juzgar que lo duro se ablanda al humedecerlo»? Acaso « ¿revisten su palacio de musgo o de plumón sin prever que los tiernos miembros de sus polluelos estarán así más mullidos y cómodos?». No puede negarse esta destreza natural de «nuestros compañeros», no puede impugnarse lo que nos une a ellos. «Nuestro llanto es común a la mayoría de los animales», afirma. En cuanto al habla, bien es cierto que en ellos no es natural, pero «tampoco es necesaria». No la precisan para «quejarse», para «pedirse ayuda mutuamente», para «invitarse al amor». Igual que nosotros les hablamos a ellos, de muchas maneras ellos nos hablan y responden, «mediante unos vocablos distintos». ¿Acaso no «se paran dos hormigas a hablar y se preguntan por su camino o por su suerte»?

\section{Ciencia y continuidad: estudios comparativos}

Este discurso de Montaigne que acabamos de glosar es de una gran modernidad, porque es idéntico al que tiene la ciencia contemporánea. Sabemos que, 
bajo el paradigma evolucionista, la ciencia se esfuerza por destacar la continuidad entre el hombre y el resto de los animales, de los seres vivos. Sin duda, este lazo entre animales humanos y no humanos parece al hombre de ciencia en nuestros días tan evidente como le parecía al filósofo francés, a fines del Renacimiento. Existen homologías genéticas y actuaciones analógicas insoslayables: ¿es que los animales no piensan, no construyen herramientas, no se transmiten cultura? ¿es que los animales no ríen? «En nuestra prisa por destacar que los animales no son personas, nos hemos olvidado de que las personas son también animales», declara Frans de Waal (De Waal, 2016). Y esta declaración pone de relieve un aspecto básico de la perspectiva científica en el análisis del ser humano: que hay una prosecución entre animales y hombres, y que su fundamento es la unidad de la naturaleza. En el pasado, se la consideraba un resultado de la propia acción creadora de la divinidad, que habría dejado un aire de familia en su obra, igual que el artesano en todos los productos que egresan de idéntico taller. En nuestros días, se juzga consecuencia de una misma estructura biológica, paulatinamente diversificada, pero que sigue sostenida en los mismos «ladrillos» biomoleculares, en las mismas o parecidas estructuras anatómicas, fisiológicas y neurológicas.

Hace poco más de un siglo, en 1913, Wolfgang Köhler, psicólogo experimental, se trasladó desde Berlín a la Estación de Antropoides de Tenerife, en las Canarias. Allí se convertiría en pionero del estudio psicológico comparativo con primates. Lo dejó reflejado en su obra clásica Intelligenzprüfungen an Anthropoiden, de 1917. Este estudio de Köhler ponía de relieve la semejanza entre el hombre y sus ancestros evolutivos. Lo más interesante del trabajo era, para su autor, la aptitud que mostraban los simios a la hora de combinar instrumentos con que enfrentarse a la resolución de problemas. Köhler pretendía hacernos comprender que el desarrollo de ciertas capacidades no se da en el hombre desde el grado cero, sino que ha aparecido ya, en un determinado nivel, durante el curso de la historia evolutiva (Köhler, 1989). Y hoy sabemos que no se trata solo de facultades intelectuales. Los profesionales que estudian a los primates en su hábitat natural describen también la preocupación que muestran cada vez que uno de ellos está herido: cómo le llevan comida o caminan más despacio a su lado para ayudarle en sus dificultades. Los que analizan su comportamiento o realizan experimentos en cautividad o 
semicautividad, como es también el caso del citado Frans De Waal, documentan fehacientemente el origen de la moralidad en la historia evolutiva (De Waal, 1997). El etólogo holandés no cita a Montaigne, pero sí es consciente de otro ilustre precedente anticipador de sus ideas: el del filósofo empirista escocés David Hume (De Waal, 2009).

Cierto es que estos científicos no evitan señalar las diferencias que se encuentran, de cuando en cuando. Por ejemplo, es curiosa la observación del psicólogo alemán sobre monos que juegan a «molestarse» con palos y más tarde, cuando el juego se transforma en pelea franca, abandonan estas posibles «armas» para agredirse con manos y pies y dientes (Sabena/Freiberg, 2008). Aquí el peso de la naturaleza, las profundas ataduras instintivas del cuerpo en los simios, parecen borrar de un plumazo los atisbos de habla, de representación abstracta o de técnica, que los investigadores empíricos se solazan en destacar. Pero, sobre todo, los naturalistas se concentran en experimentos con hormonas o neurotransmisores, comunes a todos los mamíferos, para atribuir a la oxitocina, tomemos por caso, una capacidad esencial en la mejora de los vínculos sociales entre primates, roedores o humanos. Los científicos se especializan principalmente en compilar actuaciones analógicas que son observables en el mundo natural, como el empleo bastante general de herramientas o el de ejecutorias imitativas y empáticas, muy similares entre especies diferentes. Neuronas espejo u otras estructuras biológicas comunes y equivalentes son los hallazgos que ameritan su docto empeño.

A fines del Renacimiento, Michel de Montaigne, en esta misma dirección, la de la continuidad interespecífica, apela a una vieja autoridad, la de Lucio Cecilio Firmiano Lactancio. Este escritor latino, que llegó a ser preceptor de Crispo, hijo de Constantino el Grande, nos legó una obra larga, las Instituciones divinas, en siete libros, que constituyen una defensa racional del sistema de la doctrina cristiana. En la Apología de Sibiuda, Montaigne lo cita como defensor máximo de la continuidad natural. Lactancio «atribuye a las bestias, no solo el habla, sino también la risa», escribe el francés (Montaigne, 2014: 893 y ss). Y, para dejar claro su propósito, Montaigne afirma que pretende «restituirnos y unirnos al conjunto de las criaturas»: que «no estamos ni por encima ni por debajo del resto». Por si algo faltase, apela a la autoridad de Salomón, quien sostiene (en Eclesiastés) que «todo cuanto está bajo el cielo, 
está sometido a las mismas leyes y a la misma fortuna». Es verdad que, como Köhler, Montaigne reconoce también alguna diferencia, ciertas categorías y grados, pero esto es siempre «bajo el rostro de una misma naturaleza». «De iguales hechos», escribe, «debemos inferir iguales facultades, y confesar por tanto que el mismo criterio, el mismo método que seguimos para actuar es también el de los animales». Múltiples ejemplos siguen a continuación, de zorros y cigüeñas, de caballos y perros, de tencas y lucios, de liebres y serpientes, de corzos y leones... todos para probar el hecho que venimos comentando: que somos los humanos, pesando más que el peso de nuestra vanidad, criaturas al lado de las otras, sujetas a reglas semejantes por el autor del mundo. Precisamente, lo que, de modo análogo, mutatis mutandis, podemos encontrarnos en el panorama científico de nuestro tiempo: que somos producto del mismo proceso evolutivo, una forma de vida al lado de otras sujeta a los mismos dictados de adaptación al medio y selección natural.

\section{Filosofía y especificidad: análisis comparativo}

Sin embargo, Lactancio, en el capítulo X del libro tercero de sus Instituciones (Lactancio, 1757: 71 y ss.) al que se refiere Montaigne, lo que se esfuerza en argumentar es una notable especificidad humana, una propiedad peculiar, que no es precisamente la que esperamos ver reivindicada en el análisis científico comparativo. Al contrario, lo más discernible en la primera mirada, sostiene, es similar y puede ser hallado sin dificultad entre las bestias. Los animales entienden y distinguen sus propias voces por marcas peculiares entre ellos: pueden verse sus conversaciones, puede observarse cómo se saludan, se entregan amor e indulgencia, tienen en consideración el futuro, se preparan comida, evitan los peligros, saben acechar, construirse diestramente sus moradas, fortificarlas, disponerles varias salidas... Los animales dan muestra de desear lo útil, de albergar indicios de razón, de entender. Lo que explica que puedan engañarse entre ellos y que puedan engañarnos a nosotros, 
que obedezcan a sus «reyes» y se conduzcan con prudencia. No obstante, carecen para Lactancio de una marca principal: no tienen religión. Si un rudimento de razón les ha sido entregado es para proteger su vida, mientras que para el hombre la razón es, de modo particular, la llave de su prolongación. Nada hay más específico en nuestra especie que el conocimiento y la adoración de Dios. Todo lo demás podemos encontrarlo en las demás especies. $\mathrm{Y}$ es aquí donde debe contextualizarse la referencia de Montaigne a la existencia de la risa animal, una referencia que se basa en el rétor latino y que dice literalmente: «Il me semble que Lactance attribue aux bêtes, non le parler seulement, mais le rire encore» (Montaigne, 2014: 892).

La risa, bajo la autoridad de Aristóteles, venía considerándose desde la antigüedad uno de nuestros rasgos más característicos. En el libro Sobre las partes de los animales, el discípulo de Platón escribe: «La razón de que sólo el hombre tenga cosquillas es la finura de su piel y que el hombre es el único animal que riè (Aristóteles, 2010: III, 10, 673a). El estagirita sienta aquí la tesis que convierte la risa en un proprium humano. La considera un atributo especial, inseparable de nuestra especie. Y muchos, después que él, siguieron el aserto, que rueda de Galeno a Porfirio, de Laurent Joubert a François Rabelais, de Hazlitt a Baudelaire, de Nietzsche a Bergson o a Alain. Lo más sorprendente es que también está, de alguna forma, en Montaigne. En el capítulo 50 del libro I de sus Ensayos escribe: «Notre propre et péculière condition est autant ridicule que risible». Verdaderamente, ser tan dignos de risa como capaces de reír es nuestra propia y peculiar condición.

¿Qué decir entonces de Lactancio, el erudito en quien se apoya el perigordino, para atribuir también la risa a los animales? «Il me semble que Lactance...», es lo que escribe Montaigne. «Me parece», es lo que llega a afirmar. Porque Montaigne no ha leído a Lactancio. La referencia al autor de las Instituciones Divinas es indirecta y procede de un diálogo de Benedetto Varchi, L'Ercolano. Varchi fue otro humanista, italiano, coetáneo de Bunel, muerto en 1565. Se trata de un compañero de desventuras de Maquiavelo, algo más joven, pues también formó parte activa de la República de Florencia y, al volver los Medici, la segunda vez, se vio obligado a huir a Padua. Esto fue en 1537, justo el año en que Bunel abandonaba la vecina ciudad de los canales. Sabemos que se trata de la obra de Varchi porque hay una cita inmediatamente 
anterior en los Ensayos que procede también de ella. Es una referencia que viene de Dante y que ya hemos consignado: la que se refiere a esas hormigas que se cruzan e interrogan acerca de su suerte o su camino. También deducimos que no ha leído directamente a Lactancio porque la cita que le atribuye es errónea. Montaigne piensa que el apologeta imputa la risa a los animales, pero lo que este escribe es: «Ridendi quoque ratio apparet in his aliqua» (Lactancio, 1757: 71-72). Es decir, no que los animales rían, sino que hay en estos «una cierta apariencia de reir», que es justamente lo que de hecho sucede, como vamos a argumentar a continuación.

\section{Una expresión humana, una dual etiología}

La risa es un comportamiento corporal, una señal, un síntoma, un elemento de comunicación, una expresión y una performación emotiva, esto último por sus efectos pragmáticos o realizativos en varios niveles. Por ejemplo, en la producción del gozo, la alegría, la comunión social o la propia risa. Como conducta del cuerpo es una pauta de acción que responde a otra acción o estímulo a través de un aparato efector, secretor o dinámico. Es una respuesta inconsciente, involuntaria e innata, que manifiestan, en su esbozo elemental, incluso los niños sordociegos a la misma aproximada y muy temprana edad en la que surge en los bebés que podrían haberla imitado o adquirido, utilizando la vista o el oído. Hablamos aquí de la risa incipiente y la sonrisa. Risa y sonrisa no son la misma cosa, aunque hay una evidente relación entre ellas y la intensidad de la emoción hilarante que expresan. A niveles muy bajos, se produce una sonrisa, una risa interior o secreta (subrisus), una pequeña risa (lächeln). A niveles más altos, puede llegarse hasta la risa franca e incluso hasta la estrepitosa carcajada, que viene unida a una diversidad de movimientos corporales y a un rostro enrojecido.

La risa, como fenómeno muscular, se compone de un conjunto de contracciones espasmódicas de los elevadores y abductores cigomáticos, acompañadas de tensiones y distensiones bruscas del diafragma, y de más retracciones de la laringe y la epiglotis. Es una réplica básica, condicionada 
biológicamente y dependiente de un mecanismo neurológico en el que no menos de quince efectores faciales se coordinan según un patrón estereotipado que se acompaña con respiración alterada, lo que afecta a otra buena cantidad de músculos torácicos. Experimentadores modernos han comprobado que la estimulación eléctrica del cigomático mayor (el principal músculo elevador del labio superior) produce, variando la intensidad de la corriente, todo el rango de expresiones faciales, desde la sonrisa apenas visible hasta la abierta y ancha, llegando finalmente a las contorsiones de la risa explosiva. Otros trabajos científicos relacionan el control de la risa con zonas antiguas del cerebro, implicadas también en la génesis de la conducta emocional. Helmuth Plessner, queriendo subrayar este carácter corporal, básico y elemental de la risa, un rasgo condicionado, forzoso, incapaz de evolucionar, la denomina «erupción» (Plessner, 2007: 29). Ya en autores como Joubert se deja constancia de una observación elemental: que muy a menudo la risa se nos escapa, que es un poder que no siempre se puede resistir ni retener, y que con su violencia sacude y agita todo el cuerpo (Joubert, 2002: 35).

Pero, como expresión emotiva, la risa humana es dependiente de una dual etiología: física, generada por la excitación lúdica y las cosquillas (o por la acción de químicos diversos como el óxido nitroso); y psíquica o mental, que principia en el estado de ánimo y en el contexto social, y remata en la captación del elemento cómico o gracioso en la realidad. Interviene aquí una sofisticada facultad, un talento llamado «sentido» del humor. Ciertamente, al ser un fenómeno muscular, la risa puede desencadenarse, como hemos dicho, mediante estímulos puramente físicos, como ocurre con las cosquillas, la inhalación de óxido nitroso o "gas de la risa», o con ciertas patologías que producen deterioro del cerebro. Pero esta precoz y estereotipada aparición físico-biológica no es óbice, en nuestra especie, para el desarrollo posterior de una compleja modulación emocional e intelectual. La risa humana es también resultado de elaborados chistes y de complejos juegos de palabras que cuesta entender. Y esto nos causa admiración. Muchos interrogantes se ciernen sobre esta doble causalidad. Hay en ella, como en nuestra propia naturaleza, un componente orgánico-funcional y un componente mental y cultural, derivado de la inteligencia y del sistema social en que nos constituimos como sujetos humanos. La risa propia del hombre surge a partir de desencadenantes 
cognitivos, humorísticos. En este segundo componente se asienta lo más definitorio y específico de nuestra conducta: la risa es expresiva y emotiva, es una «expresión emocional del intelecto» (Valls, 2015: 141), un índice de los procesos internos característicos de la compleja naturaleza humana. La risa es señal o síntoma, y en ella pueden localizarse elementos peculiares de regulación y de control social, ingredientes normativos estables de empleo en la comunicación y en la interacción. No obstante, también en el primer componente orgánico-funcional, hay atributos que no pueden encontrarse en ninguna otra especie animal. En este plano físico-biológico, la risa humana tampoco tiene parangón, como vamos a ver. De ahí que, en tanto comportamiento corporal específico, pueda contribuir de igual modo a clasificarnos y a comprendernos. Por eso, la utilidad filosófica de su análisis.

Como conducta, lo más significativo de la risa es la emisión de ciertos sonidos, con una forma y ritmo también particulares. Porque la risa es, sobre todo, un movimiento que produce sonidos. Unos sonidos que tienen estructura y mecanismos de generación característicos, que luego vamos a describir. La risa, nadie puede dejar de percibirlo, cursa con una alteración del rostro, del ritmo cardíaco y de la respiración; con un ensanchamiento de la boca, destello y humedecimiento de los ojos. En muchas ocasiones, veremos el rubor de las mejillas, las sacudidas del pecho, los enérgicos empujes del diafragma, las venas hinchadas del cuello, un cierto temblor de miembros o incluso una gran agitación en brazos y piernas, con contracción del vientre, y hasta dolor y sudor, y otras liberaciones incontroladas de humor corporal. La risa, como movimiento conductual, atañe al cuerpo entero, pues por él se produce y expresa. Es respuesta somática a una pluralidad de causas, pero la mayor parte de ellas no son de naturaleza física, sino mental o psicológica. Lo cual es enigmático. Incluso en el plano orgánico es misterioso que la risa sea el resultado de una fenomenología excitante, que curse con aumento de la adrenalina y noradrenalina, con incremento del ritmo cardíaco y la presión sanguínea, la tensión muscular etc., como ocurre con los mecanismos de lucha o huída, y que luego no sea realmente una preparación para la actividad, sino más bien todo lo contrario: que sea un mecanismo discapacitante, $y$, como tal, impida, no promueva, la posibilidad de una respuesta violenta y agresiva. Esto no dejará, como señal comunicativa inconsciente, de tener peso profundo en nuestra 
interacción. Así, la risa se convierte en un signo social de buena disposición y talante positivo, porque identifica una actitud no violenta, al menos en el interior de los grupos, asociaciones o comunidades étnicas y culturales. En este sentido, es una herramienta de acción performativa. Pero resolver el enigma de la risa, en todas sus dimensiones, supondría resolver el enigma de la condición humana: el misterio de un dualismo dimensional estrechamente integrado en una unidad substantiva. Como toda expresión, como expresión humana, la risa mantiene una intrínseca relación con el cuerpo, pero también pone de manifiesto, en el mismo acto expresivo, la existencia de algo que no es sencillamente corporal. Algo que nos permite inducir un trayecto desde la exterioridad a la intimidad humana, a nuestra dimensión mental y psicológica.

\section{4. «Risa» animal y risa humana}

A pesar de esto, varios científicos han colegido de sus investigaciones que la risa se encuentra en el mundo animal. Jan Panksepp afirma que la risa es la mejor medida que tenemos del placer social en los animales (Panksepp, 2005). Este psicólogo, psicobiólogo y neurocientífico estadounidense, nacido en Estonia, acuñó el término «neurociencia afectiva» para identificar la rama científica que estudia los mecanismos neuronales de la emoción. En uno de sus experimentos con ratas encontró que estos roedores muestran señales de miedo cuando se coloca un pelo de gato cerca de ellos, incluso aunque jamás hubieran estado en contacto con estos felinos, lo que parece indicar una programación genética muy específica contra sus predadores. Si se realiza el experimento usando pelo canino, las ratas no muestran ninguna señal de miedo. En otro estudio aún más famoso, este científico investiga la «risa» de las ratas. Sostiene que los circuitos neuronales que controlan la risa se hallan en las regiones más primitivas del cerebro; que ratas, perros y chimpancés nos ofrecen evidencia suficiente de que la risa y la alegría no son rasgos exclusivamente humanos; y que los niños pequeños, cuyo sentido semántico del humor es todavía muy marginal, ríen y chillan abundantemente en sus contiendas lúdicas, como las que se producen en juegos de persecución, con el perseguido riendo típicamente más que el perseguidor (igual que el comediante ríe menos que el público). Defiende que este mismo patrón es el que 
puede hallarse en el mundo animal (por ejemplo, cuando los chimpancés se persiguen o se hacen cosquillas los unos a los otros). Concluye que los sonidos de juego de estos y de otros mamíferos «se parecen a la risa humana».

Este «parecerse» no es una categoría muy científica, pero las cosquillas, es verdad, son un fenómeno al que no «parecen» ajenos los animales, a pesar de lo que dice Aristóteles. Muchas especies de mamíferos son sensibles a las molestias ligeras y cosquillosas que causa un insecto que se desliza sobre su piel, pero ya no es tan claro que respondan a las propias cosquillas que podemos provocarles igual que lo hacemos nosotros: con risas intensas y espasmos. Los primates, a pesar de su proximidad evolutiva con el hombre, no emiten vocalizaciones del estilo de las carcajadas humanas, sino más bien jadeos y aunque el jadeo pueda recordar a algunos la risa humana, no es tan sonoro, ni tan persistente, ni tan complejo sonográficamente como esta respuesta antropológica. Por otra parte, no hay nunca analogía que esté libre de sospecha, y siempre es discutible la pertinencia y el grado de semejanza, cuestiones ambas difíciles de establecer y/o medir. Precisamente por eso, siempre acecha el peligro de convertirnos en víctimas de ideas falsas sobre el funcionamiento interno de los demás animales al describir su comportamiento en un lenguaje que se adapta a nuestra forma de vida. Porque también el relincho del caballo nos recordará la risa, igual que hay risas de persona que suenan a relincho, o rápidas y atolondradas conversaciones que emulan el cacareo de un gallinero.

Volviendo al caso de las ratas que ríen, relata el doctor Panksepp que en sus correrías bulliciosas vienen a acompañarse de un cacofónico chirrido de, exactamente, 50khz, lo que, según él, refleja «positive emotional feelings» (sic). Esta atribución de sentimientos está basada en un análisis sonográfico que «parece» indicar que algunos chirridos son más alegres (joyous) que otros. Hay en esta manera de expresarse de Panksepp una censurable despreocupación por la terminología, pero lo que nos interesa es considerar su principal hipótesis: que estos sonidos emitidos en el juego son la forma ancestral de la risa. La prueba es que las ratas, ante cosquillas inducidas por humanos, emiten un idéntico chirrido de $50 \mathrm{khz}$. Esto es sin duda interesante y da qué pensar, porque además las ratas que son sometidas a cosquilleo por el experimentador quedan vinculadas emocionalmente con él y condicionadas a buscar más cosquillas, como suelen hacer los niños pequeños. Y las ratas prefieren pasar más 
tiempo con animales de su especie que emiten esos chirridos que con los que no lo hacen. Conjetura este autor que el chirrido podría ser provocado por el gratificante «cosquilleo» neuroquímico de la dopamina, como igualmente ocurre en el regocijo humano. $\mathrm{Y}$ añade que los roedores adultos son menos proclives a las conductas jocosas que los jóvenes, como también sucede en humanos. Panksepp declara, en un nuevo arranque antropomórfico, que los roedores adultos no tienen el mismo «sentido del humor». No obstante, este investigador reconoce en el ser humano una específica capacidad para la broma verbal, y que esto refleja más altas y refinadas habilidades córtico-cognitivas que las que exhiben las ratas. Aunque las palabras puedan «cosquillear» también los circuitos más primitivos de nuestro cerebro cuando aprendemos a tomarnos el pelo con ellas, y aunque esto se pueda relacionar con otras payasadas más rudas y primitivas en ratas, lo que no puede negarse es que en el ser humano se han desarrollado nuevas conexiones sinápticas, en y desde las esferas superiores, con los circuitos que controlan la risa al nivel subcortical. De otra forma no tendría sentido que se resuelva en risa, es decir, en un comportamiento físico que controlan algunas de las regiones más primitivas del cerebro, ciertas ambigüedades o equivalencias lingüísticas inesperadas, que han sido solo posibles a partir del desarrollo de la corteza cerebral más evolucionada.

Panksepp conjetura mucho en el trabajo citado y no deja de recurrir al materialismo prometedor, porque no está probada convenientemente la conexión determinante que los circuitos cerebrales subcorticales ejerzan en el control de la risa avanzada en humanos, o la dependencia de sus condicionantes químicos. Sobre todo, tendría que tenerse en cuenta que hay algo más allá de la excitación que produce en animales jóvenes el comportamiento lúdico; que hay algo notoriamente distinto de la agitación e irritación nerviosa que producen las cosquillas, acompañadas de una cierta sensación de placer si están medidas. La misma sensación placentera de lo que es en parte, para estos animales, caricia física. Sensibles, al fin y al cabo, como todos los mamíferos, esto es más bien lo que creemos que reflejan los chirridos de las ratas de Panksepp, cuyos lazos con la conducta lúdica humana elemental no pueden ser, por otra parte, negados. Al trascender la simple agitación físico-lúdica, el sentido del humor intelectual, los juegos conceptuales, no constituyen el 
mismo tipo de actividad jocosa que las bulliciosas correrías de las ratas jóvenes. Esto es evidente. Pero es que, además, ha de señalarse que en el hombre hay una diferente reacción física al jadeo o chirrido animal, producto de la agitación nerviosa con una alteración respiratoria consecuente. Aunque esto se dé también en nuestra especie, la risa humana, la risa propiamente dicha, lo que todos entendemos por risa, no es chirrido ni jadeo, sino que tiene una composición vocálica inexistente en el mundo animal.

Cierto que, entre los animales hay vocalizaciones, por ejemplo en los perros. Cualquiera puede hallar gruñidos y aullidos, además de ladridos, pero Patricia Simonet dijo haber encontrado, además, una forzada actividad respiratoria que ella denominó «risa canina» (Simonet, 2005). Aparece, según esta investigadora, en el saludo amistoso y en el inicio del juego entre ejemplares de esta especie. Es posible también encontrarla en el contacto con humanos, que pueden, a su vez, imitarla y conseguir resultados muy parecidos a los que consiguen los canes estimulando a otros a seguirlos en sus encuentros lúdicos. Los perros que escuchan este sonido, incluso el imitado y emitido por humanos, ponen «cara de juego» y persiguen al emisor o se arquean en señal de recreo, sea con otro perro o con un humano. La investigación de Simonet comenzó grabando estas vocalizaciones lúdicas y reproduciéndolas en perreras, comprobando que mejoraban el estrés canino y contribuían a reducir el tiempo de estancia de los animales sueltos o abandonados en los depósitos (porque lograban antes la adopción). En su trabajo revela cómo aumentaba, en general, su comportamiento pro-social al escuchar este sonido que viene acompasado de actividad lúdica. Esta «risa perruna» es una exclusiva de los entornos de juego y saludo amistoso, no de otros entornos. La utilizan, probablemente, para inhibir posibles respuestas agresivas entre socios de la actividad lúdica. Simonet dice que es un estímulo tan poderoso que la imitación humana puede servir también para comenzar el juego con perros, sin el empleo de ninguna otra señal. Por eso, este estímulo grabado fue usado para cambiar la conducta en perreras, reduciendo el estrés y contribuyendo a una menor duración de la residencia obligada en estas instituciones de salud pública.

Pero, de nuevo, hemos de señalar algunas diferencias en comparación con la conducta humana. La expresión facial de «risa» en los perros es siempre 
señal de no hostilidad. Simonet, reporta observaciones realizadas con elefantes asiáticos, emisores de similares sonidos respiratorios, más cadenciosos y suaves que los perrunos, pero igualmente característicos de los momentos de juego, tanto del juego solitario, como del juego social. Es una conducta parecida a aquella de las ratas, reportada por Panksepp, producto de la fogosidad e incluso del placer que acarrea la actividad lúdica, la del contacto físico cosquilleante. No hay aquí nada más allá de este reflejo sonoro o respiratorio determinado por la excitación nerviosa y el agrado que produce el juego. Por contra, la risa humana, que puede ser expresión y reflejo de estados emocionales semejantes de juego y amistad, también puede acompañar otros contrapuestos de hostilidad. Y no agotamos con ello nuestro complejo repertorio expresivo. En realidad, la «risa» perruna puede ser descrita igualmente como suspiro o jadeo (pant). Aunque Simonet busca la distancia entre ambas cosas con un análisis espectrográfico en el que se aprecian algunas diferencias, otros investigadores no dejan de señalar la cercanía. Un trabajo de Rooney, Bradshaw y Robinson (2001), citado por ella, recoge la observación de que los humanos pueden iniciar el juego con perros utilizando suspiros. De esta forma se recoge un porcentaje de éxito del 56\%.

En cualquier caso, chirrido, suspiro, jadeo, o señal respiratoria específica, parece ser lo único que puede encontrarse en otras especies no humanas y en el mismo idéntico entorno comportamental: el de la conducta lúdica. Son muestras innegables de excitación nerviosa y así fue señalado, muchos años antes de que Simonet iniciara su investigación, por el etólogo y premio Nobel Konrad Lorenz, en su obra Cuando el hombre encontró al perro (Lorenz, 2019). Lorenz ya había observado que una invitación al juego provoca en el perro una apertura de las mandíbulas cuyo ángulo inclinado, que se extiende casi de oreja a oreja, y la lengua expuesta, recuerda en los humanos a la risa. Si esta invitación es producida por un amo apreciado, la emoción es tanta que pronto el perro empieza a jadear. Esta es la «risa» de Simonet que Lorenz describe como resultado de un enardecimiento. Stanley Coren, profesor de psicología en la British Columbia University, llama «jadeo» (panting) a esto que Lorenz identifica con la risa humana (a sort of breathy panting that can escalate to a more guttural "ah-grunting" if intense..., Coren, 2009). Igualmente recoge observaciones de Darwin sobre chimpancés y «sonidos 
parecidos a la risa». Son los mismos que Jane Goodall describe como una suerte de jadeo entrecortado, que puede transformarse en un gruñido gutural si llega a ser lo suficientemente intenso. El consenso general es que esta risa de mono suena algo así como una respiración pesada. Es resultado, una vez más, del juego vigoroso, y se convierte en señal de intenciones lúdicas. Robert Provine diferencia también entre los sonidos cortos del «ja, ja» humano y los jadeos simiescos que son más largos, y suenan con cada aliento interno y externo (Provine, 2001). De entrada, nadie sin aviso ni expectativa recordaría la risa humana al escucharlos. Están muy alejados de la complejidad etiológica, contextual, gestual y sonora de nuestra risa. Nuestra risa no es en modo alguno un jadeo y se halla muy distante también de la simplicidad de funciones que cumple en el mundo animal. Tal vez por eso, Laurent Joubert considera «bastarda o ilegítima» esta risa de perro, de la que ya se hablaba en su época. Joubert, nacido en 1529, en el Dauphiné, se formó como médico en Montpellier y llegó a ser el físico personal de Catalina de Médicis y, más tarde, uno de los que cuidaban al propio rey de Francia. Autor prolífico de obras médicas en latín y en francés, Joubert es quizá el primer ensayista científico sobre el tema de la risa, y piensa que la «risa canina» es mera risa gestual. En ausencia de materia risible, es una simple convulsión, como la que provocan causas externas, tal que el uso de la planta sardonia (ranunculus sceleratus) o las picaduras de ciertas tarántulas. «No es risa verdadera, dice, como tampoco es hombre un hombre pintado» (Joubert, 2002: II, 3). Conviene asimismo apuntar que el juego canino ya iniciado viene seguido no solo de una señal respiratoria jadeante, sino que viene acompañado también de los simples ladridos, del sonido habitual, característico y general de la especie. El mismo sonido que podemos escuchar en sus encuentros agonísticos, tan distantes de los lúdicos, salvo en el incentivo de la actividad nerviosa. Igualmente se emiten en el juego arrancado los gruñidos característicos.

¿Y qué decir de las vocalizaciones de otras especies? ¿Qué podemos encontrar fuera de la clase mamífera? Raoul Schwing y su equipo de colaboradores en el Instituto de Investigación Messerli, de la Universidad de Medicina Veterinaria de Viena, estudió a los loros kea (Nestor notabilis), una especie de ave psitaciforme de la familia strigopidae, oriunda de Nueva Zelanda, animales muy inteligentes y dotados de gran curiosidad. Este loro listo 
e inquisitivo es capaz de hacer que otros de su especie rían. Esto es lo que encontramos en la divulgación popular de los trabajos de Schwing (Bates, 2017). Pero, en realidad, lo que este científico descubrió es que los loros kea tienen una llamada específica que pone a otros loros que la escuchan en disposición de juego. Lo que algunos interpretan como «buen humor», es un sonido que emiten en la relación de juego. Con mucha probabilidad se trata de una expresión de algo parecido al placer o agrado. Los investigadores del Instituto Messerli hicieron grabaciones de estas llamadas lúdicas y cuando se las ponían a otros kea estos mostraban un cambio de comportamiento proclive al juego. A veces se animaban de inmediato y empezaban a jugar con las aves más próximas, lo que indica que la llamada afecta a sus emociones y que las pone en un estado de ánimo «juguetón». En cierto modo, esto recuerda las reacciones humanas a las risas enlatadas de los shows televisivos. Hay que señalar que este loro destaca por su intensa conducta lúdica, que juega incansablemente con objetos en solitario, manipulándolos con el pico o con las patas, que los arrojan a otros kea, y que en el vuelo es proclive a la persecución y la acrobacia (Schwing et al., 2017). Está claro que los kea son animales inteligentes y sociales, pero en ellos no hay más de lo que se ha observado entre perros y simios: una expresión de emociones en el trance de la conducta lúdica. La risa tiene entre nosotros una función parecida, es verdad. Pero el sonido de estas aves es una especie de chillido y no se parece mucho a nuestra propia risa.

Mucho más identificable y próximo a nuestras proferencias lúdicas es el sonido que efectúan las hienas, que es el tipo de «hilaridad» animal más conocido popularmente. Las hienas manchadas (Crocuta crocuta) son carnívoros gregarios, de vida principalmente nocturna, que viven en grupos sociales de hasta 90 individuos y son clanes que dominan las hembras, dentro de los cuales una red de comunicación les informa sobre su identidad y estatus social, facilitando la interacción. No son cánidos, frente a lo que suele pensarse, sino animales feliformes. Nicolás Mathevon, profesor de la Universidad de Lyon/St. Etienne y senior member del Instituto Universitario de Francia, ha investigado esta «risa» de las hienas junto con Frederic E. Theunissen, que pertenece al Departamento de Psicología de la Universidad de California /Berkeley y dirige el laboratorio de ciencia acústica de dicho centro académico. 
Lo que encontraron es que esta «risa de hiena» se emplea principalmente durante la alimentación, para establecer los derechos y organizar las actividades de recolección de comida, porque en esos momentos se genera una intensa competencia y acontecen peleas por los despojos de las presas. De hecho, lo que algunos consideran sus carcajadas, en realidad son sonidos de estructura más variada y compleja, que se emiten fundamentalmente cuando un animal subordinado es atacado y marginado por un individuo dominante de su manada en las horas de nutrición: es el conflicto el que los provoca (Mathevon, Theunissen et al., 2010). En su muy jerarquizada sociedad de cazadores, los ejemplares dominantes son los primeros en aparearse y comer. Y suele haber conflictos por el poder, por subir y bajar en la escala social, por acceder a los recursos. En este trance emiten unas vocalizaciones que recuerdan vagamente la risa humana. Tienen las hienas, en conjunto, más de diez diferentes vocalizaciones, unas incluidas dentro de las otras, lo que hace difícil su clasificación. El contenido de información completo que contienen no se ha desentrañado en su totalidad. Pero las que se denominan sus «risas» son en realidad sonidos agudos emitidos en las pugnas que tienen lugar cuando las hienas se alimentan juntas de una presa. Siendo la suya una jerarquía salvaje, los subordinados son apartados con frecuencia y se les niega el acceso a la comida. Típicamente, su «risa» es el sonido emitido por el animal de menor rango frente a otro dominante. Dado que se trata de animales de hábitos nocturnos, las posibilidades de comunicación visual se reducen. Para interactuar y también para que los miembros de los escalafones más bajos de la sociedad de hienas «protesten», recurren a estas señales acústicas. Se trata de sonidos que pueden ser oídos a larga distancia y, aunque el estruendo que generan estos conflictos podría parecer poco adaptativo, pues descubre su éxito en la caza a otras especies depredadoras como los leones, o incluso a otros clanes de hienas, a los que se puede atraer con la subsiguiente amenaza de incrementar la disputa por el botín alimenticio, es justamente este peligro lo único que obliga a las hienas dominantes a compartir la comida, para que las que protestan ruidosamente mantengan la boca cerrada. De manera que estos sonidos ayudan efectivamente a ajustar el comportamiento conjunto en beneficio del grupo, evitando inútiles y deletéreas disputas y favoreciendo interacciones «políticas», pues son también sonidos que atraen a otros compañeros del propio clan. Como 
suele ocurrir con otros animales sociales, como los chimpancés, estos carnívoros forman coaliciones contra sus competidores para obtener y defender el rango social, lo que no está necesariamente relacionado con el tamaño o habilidad en el combate. La organización social de un clan de hienas implica una jerarquía matrilineal, igual que en los bonobos. Hablamos siempre de la hiena manchada, sobre la que se ha llevado a cabo el estudio, porque es muy instructivo señalar que la estridente «risa» se halla ausente del repertorio vocal de la otra especie simpátrica, pero menos social: la hiena marrón (Hyaena brunnea).

La mayor parte de estos datos proceden de la observación de la vida salvaje, pero la investigación sonográfica de Mathevon y Theunissen se llevó a cabo con hienas manchadas de una colonia de cría en cautividad, mantenida en la Estación de Campo para el Estudio del Comportamiento, Ecología y Reproducción (FSSBER) en la Universidad de California, Berkeley. Las «risas» grabadas para su computación se producían provocando a los animales con un hueso o un trozo de carne presentado a través de la cerca del recinto. Se trata de un sonido que se emite en series que consisten en una rápida sucesión de llamadas o notas muy cortas, pero de estructura muy rica y casi musical. Son precisamente los animales subordinados, frente a los dominantes, los que emiten el repertorio más complejo de sonidos. La dominancia de estatus y la edad son las variables principales que afectan a esta diversidad, siendo el coeficiente de variación de la frecuencia media del espectro más alto en animales subordinados que en animales dominantes, pero con una tendencia a disminuir con los años. En definitiva, la «risa» de la hiena codifica información potencial sobre identidad individual, estatus de dominancia/subordinación y edad. $\mathrm{Y}$, aunque tienen lugar sobre todo en el trance de disputa por el alimento, estas «risas» pueden ocurrir en cualquier situación, como respuesta a una amenaza agresiva. Es una señal de frustración, y esto quiere decir que la más conocida de las «risas» animales no tiene nada que ver con la risa.

Mas noticias sobre la risa en otros grupos variados de animales nos ponen en relación con búhos, suricatas, pingüinos, camellos, delfines... A estos últimos siempre les vemos sonreír e inmediatamente les atribuimos una estrecha simpatía por nosotros. Sin embargo, es elemental la comprobación de que el gesto es una parte inmutable de su rostro: no es, por tanto, una sonrisa. Cierto 
es que a los delfines les gusta interaccionar con humanos, jugar con nuestra especie, y parecen ser también susceptibles de reaccionar a las cosquillas. Pero Michael Owren (Morelle, 2011), profesor asociado de psicología y neurociencia de la Georgia State University, apelando al sentido común, pone de relieve que tocar, acariciar o cepillar a los animales en general, puede ser placentero para ellos. Esto es algo general en nuestra clase zoológica: placer generado por el tacto. Placer, a consecuencia del roce físico, que depende, eso sí, de una medida muy precisa, traspasada la cual deviene molestia o dolor. La mayoría de los animales no pueden producirlo por ellos mismos ya que no tienen manos y dedos como nosotros. Pero esto no ocurre con nuestros parientes primates.

Volvemos a Frans De Waal, quien dice que los humanos llevamos un mono dentro y que hacer cosquillas a un chimpancé joven es bastante parecido a hacer cosquillas a un niño. El simio tiene los mismos puntos sensibles que el humano: en las axilas, en el costado, en la barriga. Abre ampliamente la boca, relaja los labios y emite un sonido con el mismo ritmo de inhalación y exhalación, dice, que la risa humana. «El simio -escribe- también muestra la misma ambivalencia que el niño. Aparta los dedos que le hacen cosquillas e intenta escapar, pero, tan pronto como paras, enseguida vuelve a por más, y se coloca con el vientre directamente delante de ti. En este punto, solo es necesario señalar a un punto con el dedo, sin llegar a tocarlo, y vuelve a darle un ataque de risa». ¿Risa? ¿Es risa? En realidad, De Waal no deja de reconocer que se trata de un sonoro jadeo (panting audibly) (De Waal, 2016). Hay aquí evidencias de similitud en cuanto a las circunstancias en que se producen ciertas reacciones instintivas en animales y humanos, y hablamos de las cosquillas y de nuestra reacción frente a ellas. Pero ni estas son todas las circunstancias que hay que considerar en la comparación, ni, incluso en estas mismas circunstancias, la reacción es completamente idéntica, pues no hay en ella apenas sonidos vocálicos, sino flujos de aire, jadeos. Ni hay tampoco exhalaciones e inhalaciones en la risa humana a pesar de lo que dice De Waal, que en esto se equivoca si hemos de dar crédito a otros competentes científicos, como Provine o Davila Ross, a los que ahora citaremos.

Antes que ellos, Charles Darwin en el capítulo VIII de su afamada obra The Expression of the Emotions in Man and Animals, había reportado que los 
simios antropoides emitían un sonido repetido que se corresponde con nuestra risa, como él mismo había observado al someterlos a cosquilleo, especialmente en las axilas (Darwin, 1889). Los movimientos de reacción a las cosquillas, dice Darwin, son actos reflejos, iguales en los bebés recién nacidos y en los niños mayores, hecho que tuvo ocasión de comprobar con sus propios hijos. Naturalmente, en esta obra, señala también la diferencia con la risa derivada de una idea cómica, de un absurdo. Reconoce que a esto no se le puede denominar «acción refleja». Volviendo al sonido al que hace referencia Darwin, suele venir acompañado de una amplia apertura de boca, con exposición de los dientes, como en los humanos. Hay una comunidad expresiva entre las especies próximas, señala. Simios y humanos mueven los mismos músculos faciales bajo un estado de gran alegría, de intenso placer. En estos casos existe una tendencia al desarrollo de ciertos movimientos o a la emisión de algunos sonidos. En los infantes, la percusión de palmas, la elevación del suelo con saltos y, por supuesto, sus sonoras carcajadas. La risa es una expresión emocional y en los perros, también tenemos saltos y ladridos, como ocurre cuando se les saca fuera de la casa, al campo abierto, para pasear. También sucede con otros animales, como los caballos. Darwin constata que esto es consecuencia principal de la propia excitación sensible que acelera la circulación y estimula el cerebro. A Spencer se remite cuando lo atribuye a la «fuerza de los nervios». El naturalista no va nunca más allá del establecimiento de relaciones entre la excitación nerviosa y el gozo o la diversión. Y, ciertamente, a este nivel tan básico, no es muy difícil hallar continuidad entre el mundo animal y el mundo humano, al menos en su estadio inicial de risa infantil. Admite que carece de una explicación para la reiteración del sonido en la risa humana (laughter) frente a lo que denomina «risa ahogada» (tittering) de los simios. En el primer caso se refiere, obviamente, a la estructura silábica de nuestra expresión hilarante. La sola mención de lo segundo ya deja establecida una diferencia. Darwin se demora mucho en el inventario de los gestos faciales que acompañan la risa, pero no es muy preciso en la descripción y categorización del sonido. Algo en lo que ha brillado, especialmente, Robert Provine. Provine, profesor de Psicología, ha trabajado en el programa de neurociencia de la Universidad de Maryland, en los Estados Unidos. «Los simios, escribe, emiten un sonido que casi nadie es capaz de identificar como risa si se lo escucha en 
una grabación». Es una especie de jadeo (panting), más similar al de los perros, que nos es a todos familiar, que a la risa humana. De compararlo con nuestra propia especie recuerda más a los escalofríos, al ejercicio de correr, o incluso al éxtasis sexual (Provine, 2001: Cap. 5). El mismo Darwin admite que el sonido producido por los simios a duras penas coincide con lo que a veces denominamos «risa silenciosa», que, ciertamente, no es un modo muy técnico y preciso de calificarla. La semejanza más notable no es vocal, no tiene que ver con la articulación del sonido, con el timbre o cualidad perceptiva del mismo, sino con su estructura rítmica, compuesta de intervalos regulares, que es lo que se denomina «reiteración del sonido» y a veces «repique» (peal). Esto, que está relacionado evidentemente con la respiración, podríamos esperar encontrarlo en primates, en la «risa» simia. Debería existir una equivalente disposición a nuestros cadenciosos «ja, ja, ja». Sin embargo, en los chimpancés, este ritmo es dos veces más rápido que en los humanos. Y la razón de esa diferencia en el acompasamiento es precisamente la que da lugar a la mayor desigualdad entre nuestra conducta y la suya: los chimpancés «ríen» durante la inhalación y la exhalación, lo que contrasta con la risa humana, que es puramente exhalatoria, espiratoria, como el lenguaje. Esta importante diferencia es algo que pasa por alto Frans de Waal. En efecto, la risa humana, igual que el discurso, solo se produce durante la espiración. Y esto marca una importante disparidad en el patrón de actividad neuromuscular responsable: los humanos hablamos y reímos modulando la espiración; los perros, los chimpancés y otros primates producen sonido, en ciertos trances de excitación lúdica, por una combinación irregular de exhalación e inhalación. Provine dice que la risa humana proviene de una «ritualización» del jadeo que aparece en los juegos rudos de nuestros antepasados antropoides. Ni el término es pertinente ni aporta prueba de corroboración adecuada. Pero puede admitirse, por elemental observación, que la risa aparece de súbito, de modo incontrolado, en los juegos infantiles de persecución o lucha, especialmente entre los que tienen cierta intensidad, que es lo que ocurre también entre los jóvenes chimpancés. Del mismo modo, sabemos que las cosquillas, cuyo parecido con esta clase de juegos es claro, desencadenan espontáneamente la risa. Pero la «ritualización» no sabemos a qué hace referencia. Sin embargo, este autor nos aporta una interesante hipótesis que afecta al origen del lenguaje y de la risa. 
Considera Provine que la restricción para la evolución del lenguaje en los simios no fue originalmente mental, lo que apenas se ha reconocido. Los simios, bípedos imperfectos, siguen cautivos de un inflexible sistema neuromuscular todavía atado a la más antigua y esencial (desde el punto de vista evolutivo) respiración. No la controlan con la precisión que es capaz de hacerlo el ser humano y esto limita la emergencia del discurso en los antropomorfos. Igualmente explica su deplorable competencia lingüística. De todos es conocida la experiencia del matrimonio Hayes en la educación del chimpancé Viki desde su infancia: después de seis años de exhaustivo entrenamiento vocal, solo producía las palabras «mom», «dad», «cup» y «up», monosilábicas y a duras penas reconocibles. Según el neurocientífico norteamericano, el obstáculo principal para la evolución del discurso de los simios depende más del dominio de la producción del sonido que de la cognición y la capacidad simbólica. También lo muestran las experiencias de Allan y Beatrix Gardner y de Roger Fouts con el chimpancé Washoe, o la de Francine Patterson con el gorila Koko, que tuvieron que utilizar para conseguir mayores progresos el ASL (American Sign Language). Igualmente, David Premack usaba símbolos magnéticos con la chimpancé Sarah, que podían adherirse a un tablero. O Sue Savage-Rumbaugh, que recurrió, para enseñar a la chimpancé Lana y al bonobo Kanzi, al pulsado de símbolos en la pantalla de una computadora. Solo así se consiguió que estos animales respondieran a cientos de preguntas del inglés hablado, pero sin que, en ningún caso, lograsen una verdadera competencia lingüística, con gramática y estructura proposicional. Mucho de este aprendizaje parece consistir simplemente en una memorización mecánica, no en un avance hacia la abstracción y la conceptualización.

Manejar la respiración es esencial para comer y beber, aparte del esfuerzo físico en el desplazamiento. Pero el gran logro humano ha sido controlarla para producir el discurso. El jadeo del chimpancé ante las cosquillas es un reflejo producido por la propia excitación. Si lo denominamos «risa», hablamos de algo bastante diferente de la risa humana. La risa del chimpancé está encerrada en el ciclo de la respiración. Lo que revela una fundamental incompetencia para modular la exhalación, que es una condición crítica también para la producción del discurso humano. Los humanos ríen como hablan, modulando los sonidos de la espiración. No es la estructura del tracto vocal, dice 
Provine, sino la combinación de neuronas y músculos lo que produce el movimiento de vocalización. Y aquí tenemos la variación humana principal: un «flojo» emparejamiento respiración-vocalización, en lugar de la rígida conexión simiesca. La evolución del bipedismo, la respiración y el discurso parecen estar muy relacionados. Los humanos han desarrollado una gran habilidad para caminar y correr, y esto se consiguió un tiempo después de la separación evolutiva respecto de los simios. Los simios no pueden caminar eficientemente. La evolución de la locomoción bípeda y el discurso (esta es la hipótesis de Provine) están relacionados causalmente (teoría bípeda de la evolución del discurso). El lazo común sería el control de la respiración, resultado de la liberación del tórax respecto de las demandas mecánicas de la locomoción cuadrúpeda y el «aflojamiento» del lazo entre respiración y vocalización. La sincronización entre el sistema locomotor y el respiratorio en humanos es mucho más sofisticada que en cuadrúpedos y eso hace también a nuestra respiración más plástica en su ritmo y más independiente en su relación con la locomoción. De esta forma, el bipedismo hubo de ser una condición necesaria (aunque no suficiente) de la evolución del discurso, porque el sistema vocal necesita más cambios. Pero fue un paso crítico. Los humanos, además, tienen más masa espinal en el segmento torácico que gobierna el cuello, los brazos y el tronco, la región implicada en el control respiratorio. El desarrollo de esta masa torácica espinal fue consecuencia de la otra demanda: el dominio respiratorio de los músculos para la evolución del discurso. Por tanto, el bipedismo apareció antes que el habla.

El estudio del desarrollo humano ofrece una prueba indirecta del lazo entre locomoción y vocalización. Levantarse solo y caminar se consigue al final del primer año. El siguiente gran paso es el desarrollo del lenguaje (que tiene también lugar en niños que no andan). Los pájaros, virtuosos vocalizadores e imitadores del discurso humano, son también bípedos, aunque su estructura pectoral y sus miembros superiores se hallen transformados al servicio del vuelo. Las ballenas, liberado su aparato respiratorio de las demandas de la gravedad, no por el bipedismo sino por la suspensión en el agua, son también capaces de notables habilidades respiratorias, como la contención del aliento por decenas de minutos, obvia evidencia de control. También es remarcable 
la capacidad humana de contención de la respiración (por uno o varios minutos), pero este control, por sí mismo, no indica facilidad vocal. Para eso es preciso pertenecer a nuestra especie. En ella se da una peculiar intersección de respiración, locomoción, habla y risa.

\section{Una modulación exclusiva}

Cuando nos enfrentamos con la tesis que afirma que la risa es algo que podemos encontrar casi por todas partes en el mundo animal, esperaríamos hallar algo más que un señalamiento de «similitudes» genéricas. Querríamos algo más que la constatación de que existe una especie de «risilla» cuando se hace cosquillas a los simios. Este sonido al que todos los etólogos se refieren es también, como ya sabemos, el que tiene lugar en el momento del juego. Y pensamos que en estos eventos nuestros parientes antropomorfos se asemejan a los humanos sobre todo porque los sonidos que emiten ocurren en el mismo lance en el que los humanos acostumbran a reír. Es decir, que es más semejante el contexto y la acción que la forma de expresar las emociones que genera. La risa humana es un comportamiento que depende, como todos, de un proceso neurológico. En dicho comportamiento, el elemento físico principal es la parte audible que consiste en una vocalización (en la sonrisa, obviamente, sería la parte visible lo que establece una diferencia básica). Esta vocalización no es un sonido cualquiera, un sonido arbitrario, sino que procede de un reducido conjunto de tipos vocálicos, lo que establece un prototipo de origen genético: es esencialmente la misma en todos los humanos. Los hablantes de las distintas lenguas difieren más bien en la percepción que en la producción de este sonido típico de la risa (igual ocurre con las onomatopeyas que describen los sonidos que emiten los animales). La risa es «ja» en español; «ah» en francés; «ha» o «ho» en inglés; «hi», «ha», «ho» o «ei» en alemán; «xa» en ruso; «hej» en checo... Pero la vocalización es estereotipada y similar, aunque no idéntica, no absolutamente idéntica. No es tampoco totalmente inflexible por cuestiones expresivas: la risa revela matices sociales, gramaticales y emocionales concretos. Hay tonos dependientes de la lengua nativa del que ríe, que son aprendidos, más que resultado del proceso neuromuscular. De ahí 
que, debido a estas variaciones (algunas de las cuales también podrían relacionarse con peculiaridades más concretas, heredables), la risa humana no se defina por un único sonido vocal específico (ja, jo, je...). Sin embargo, siempre coincide en su tendencia a una estructura homogénea de notas similares, no de notas mixtas. Y la explicación de esto es sencilla: economía. Nuestro aparato fonador desalienta una esforzada gimnasia vocal, aunque pueda haber alguna variación en la secuencia. Además, y esto es algo fundamental, entre cada nota suena un suspiro, que se corresponde con la aspiración del aire. La risa humana es exclusivamente exhalatoria y puede visualizarse como una serie de cuentas ensartadas en hilo, correspondiendo cada cuenta a una vocalización o nota de risa, procediendo típicamente con un decrescendo. Esto último tiene capital importancia porque muestra el vínculo ceñido que se establece entre risa y discurso, entre risa y lenguaje. La risa puntúa el discurso. Quiere esto decir que se esparce por él, pero no al azar, no de modo arbitrario. El discurso tiene la prioridad y el hablante es el que va dando pie a la audiencia para reír. La risa sigue a las afirmaciones o preguntas, a las pausas o finales de las pláticas. Domina el lenguaje. Podríamos pensar que esto simplemente ocurre porque se espera a esos momentos para provocarlas, pero hay más: no es solo que la risa humana siga el «timing» del discurso, y que esto sea provocado por la escalada del ritmo semántico o significativo del habla, es que la risa también sigue su ritmo físico, material, neurológico. La naturaleza exhalatoria del lenguaje se copia en la risa exhalatoria humana.

\section{Conclusión}

Para concluir, diremos que humanos y animales difieren en las situaciones sociales en las que «ríen». Esto marca otra distancia esencial entre risa humana $\mathrm{y}$ «risa» animal. La mayor parte de la risa humana se produce durante la conversación. En los chimpancés o los perros, su «jadeo» ocurre solo con las cosquillas y los juegos rudos de persecución. El contacto físico es el común denominador de la «risa» animal. En el caso humano, la risa es solo minoritariamente un producto del roce material. Tampoco el humor parece ser su causa principal, como muestra la reflexión más elemental sobre la experiencia cotidiana: la mayor parte de la risa, como decimos, obedece a una interacción 
visual y, sobre todo, conversacional. La risa funciona en la inmensa mayoría de los casos como un display social: la risa es un contenedor de signos visibles y audibles. La risa socialmente estimulada se desarrolla entre los 3 y los 4 meses justamente porque las cosquillas requieren la discriminación entre el yo y lo que no es el yo.

Después de haber considerado varios trabajos científicos sobre la «risa» animal, no vamos a negar, obviamente, nuestro estrecho lazo evolutivo. Los humanos somos también animales, y es claro que nos parecemos a ellos. En su forma elemental, la risa, como expresión de la excitación nerviosa, o del gozo o la alegría (si se desea) ante el contacto (cosquillas) o la actividad física (juegos), está presente en los animales de nuestra clase mamífera y en algunos otros, igual que en el hombre, y también en las mismas circunstancias. Las ratas expresan esta excitación con la emisión de unos agudos chirridos. Los loros con una especie de chillido. Los perros y los simios con una respiración alterada, jadeante, y, en estos últimos, en los más próximos evolutivamente, con un atisbo de vocalización. Pero hay un claro contraste entre una particularidad exclusivamente humana, la risa egresiva, y la alternancia en el «flujo de aire» egresivo-ingresivo de los simios, lo que también señala, con Darwin y Provine, la doctora Davila Ross (Davila Ross et al., 2009). Vocalizaciones animales más nítidas, como las que se dan en las hienas, no tienen nada que ver con la risa física tal como la conocemos, se atribuya a los propios animales o al hombre.

En toda forma de expresión emocional, por su relación con el dinamismo muscular, encontraremos siempre un incremento de la animación corporal, que trae consigo un ritmo más elevado de consumo de oxígeno, y expresiones sonoras que se acompañan con la apertura de la boca y la subsiguiente presentación de los dientes. Estos son rasgos que asimismo aparecen en humanos. Pero, incluso en este nivel básico, este nivel de mínimos, la risa humana nos ofrece también notables diferencias. Es característicamente vocálica y puramente egresiva en lo que respecta a la respiración, mientras que en los animales es fundamentalmente un resultado del par inhalación-exhalación, es decir un jadeo, o bien un sonido no vocálico, y sin la estructura rítmica silábica que distingue a la risa humana. Mientras que varios tipos animales chillan o jadean alterados en los mismos contextos en los que se produce nuestra risa 
elemental (cosquillas y juegos rudos), el ser humano es el único ser vivo que vocaliza de forma cadenciosa, con un compás característico que estructura el entrecorte de la respiración. Nuestra risa, como nuestro discurso, se produce a golpes egresivos de aliento. La risa se esparce en el discurso y por el discurso, lo puntúa, lo sigue y lo completa, y es el resultado, en su manifestación máxima, de la misma inteligencia abstractiva que da lugar a la palabra.

Recordando, casi parodiando, a Aristóteles, podríamos decir que los animales tienen la «voz» de la risa, pero no la «palabra» (Aristóteles, 2011: I, 2, 1253a, 11-19). Y la usan como ellos usan la voz, como un signo que refleja sus propias sensaciones. Como tal está también presente en humanos $\mathrm{y}$, en este nivel de mínimos, las semejanzas son notables, sin que en esta expresión elemental dejen de destacarse importantes diferencias. Justo las diferencias que, en el plano físico, emparentan la risa humana y las fonaciones lingüísticas: egresividad y una articulación rítmico-vocálica de la que apenas si hay rastro en los animales de la clase superior primate. Esta es la base física de una risa más propia y específica, que no consiste en la expresión de nuestras sensaciones y estados físicos, sino, sobre todo, en el testimonio de una capacidad de representación del mundo que no tiene parangón en la naturaleza

En definitiva, resulta evidente que los animales manifiestan estados de euforia y excitación con expresiones no idénticas, pero que pueden emparentarse con la risa humana. Establecemos el lazo fundamentalmente porque nosotros la empleamos en parecidos contextos con el mismo contenido y función. Es más bien desde nosotros hacia ellos como se establece la semejanza, en el plano del comportamiento y de su objeto, más que en el del parecido físico exacto de estas expresiones. Pero la risa humana, la autentica risa humana, resulta, sobre todo, de la percepción de lo humorístico, de lo gracioso. Y los animales no conocen ni el humorismo ni el ridículo. Pero este es ya el asunto de otra reflexión, precisamente de aquella que descubre la más honda profundidad de nuestra única y específica risa, la que expresa en el cuerpo emociones producidas por una abstracta y simbólica inteligencia, por el logos que influye, como dice el profesor Rodríguez Valls, en la misma constitución de nuestra corporalidad (Rodríguez Valls, 2020: 29).

\section{Bibliografía}


Aristóteles (2011) Política. Madrid: Gredos

Aristóteles (2010) Obra biológica. Madrid: Luarna Ediciones.

Bates, M. (2017) «These Parrots Can Make Other Parrots 'Laugh'—a First», National Geographic, March, 20/2017

Berger, P. (1998) Risa redentora. La dimensión cómica de la experiencia humana. Barcelona: Kairós

Caruso, C. (2016) «Rats Enjoy Being Tickled--When They're in the Right Mood», Scientific American, 10/11/2016

Castro, Sixto J. (2014) Sobre la belleza y la risa. Ensayo de ontología estética. Salamanca: Editorial San Esteban.

Coren, S. (2009) «Do Dogs Laugh? Animals make laugh-like sounds when they are tickled or playing», psychologytoday.com, 22-11-2009.

Darwin, Ch. (1899) The Expression of the Emotions in Man and Animals. New York: D. Appleton and Company.

Davila Ross, M., Owren, Michael J., Zimmermann, E. (2009) «Reconstructing the Evolution of Laughter in Great Apes and Humans». Current Biology. Published Online: June 04, 2009.

De Waal, F. (1997) Bien natural. Los orígenes del bien y del mal en los humanos y otros animales. Barcelona: Herder.

De Waal, F. (2009) «Darwin ríe el último», Nature nº 460 - Julio de 2009.

De Waal, F. (2016) «What I Learned From Tickling Apes», Sunday Review | Opinion The New York Times, April 8, 2016 - «Lo que aprendí haciendo cosquillas a los simios», El País $12 / 05 / 2016$

Joubert, L. (2002) Tratado de la risa. Madrid: Asociación española de neuropsiquiatría.

Köhler, W. (1989) Experimentos sobre la inteligencia de los chimpancés. Madrid: Debate.

Koestler, A. (1995) «Humour and wit», en Encyclopaedia Britannica, 15th Edition

Lactancio (1757) De falsa sapientia seu Divinarum Institutionum adversus gentes. Roma: Typographia Angeli Rotilii. Ver Libro III, Capítulo X, p. 71 y ss.

Lorenz, K. (2019) Cuando el hombre encontró al perro. Barcelona: Tusquets.

Mathevon, N.; Theunissen, F. et al., (2010) «What the hyena's laugh tells: Sex, age, dominance and individual signature in the giggling call of Crocuta crocuta». BMC Ecology 2010 $10: 9$

Morelle, R. (2011) «Buscan el origen de la risa... haciendo cosquillas a animales», BBC.com, 30-12-2011.

Panksepp, J. (2005) «Beyond a Joke: From Animal Laughter to Human Joy?», Presentation on June 10, 2005, at the Annual Meeting of the Rapaport-Klein Study Group, Science, 2005, 308: 62-63 (April 1, 2005)

Plessner, H. (2007) La risa y el llanto. Investigación sobre los límites del comportamiento humano. Madrid, Trotta

Provine, Robert R. (2001) Laughter. A scientific investigation. New York: Penguin Books. 
Rodríguez Valls, F. (2015) El sujeto emocional. La función de las emociones en la vida humana. Sevilla: Thémata

Rodríguez Valls, F. (2020) ¿Qué es la antropología? Sevilla: Senderos

Rooney, N. J.; Bradshaw, J. W. S.; Robinson, I. H. (2001). «Do dogs respond to play signals given by humans?» Animal Behaviour, Vol 61(4), 715- 722

Sabena, Gretel; Freiberg Hoffmann, Agustín, (2008) «Los estudios sobre la cognición en primates de Köhler: algunas repercusiones en los trabajos de Vigotsky», XV Jornadas de Investigación y Cuarto Encuentro de Investigadores en Psicología del Mercosur. Facultad de Psicología Universidad de Buenos Aires, Buenos Aires.

Simonet, P., Versteeg, D., Storie, D. (2005) «Dog-laughter: Recorded playback reduces stress related behavior in shelter dogs», Proceedings of the 7th International Conference on Environmental Enrichment July 31 - August 5, 2005.

Siurana, J. C. (2015) Ética del humor. Fundamentos y aplicaciones. Madrid: Plaza y Valdés

Schwing, R., Nelson, X. J., Wein, A., \& Parsons, S. (2017). «Positive emotional contagion in a New Zealand parrot». Current Biology, 27(6), R213-R214.

\section{Luis Fernández Navarro lufenayo@gmail.com}

